\title{
REGULASI ANTIMIKROBA SISTEM PROSPEKTIF (RASPRO): SISTEM TATA GUNA ANTIBIOTIK UNTUK KENDALI MUTU DAN KENDALI BIAYA DI RUMAH SAKIT SEBAGAI UPAYA MENURUNKAN BEBAN BPJS KESEHATAN
}

\author{
WIDYAWATI LEKOK ${ }^{1}$ \\ RONALD IRWANTO NATADIDJAJA2,3 \\ ANTI DHARMAYANTI 3 \\ ${ }^{1}$ Trisakti School of Management, Jl. Kyai Tapa No. 20, Jakarta, Indonesia \\ ${ }^{2}$ Fakultas Kedokteran Universitas Trisakti, Jl. Kyai Tapa No. 1, Jakarta, Indonesia \\ ${ }^{3}$ RASPRO Indonesia Study Group \\ wlk@stietrisakti.ac.id, ypri.raspro@yahoo.com
}

\begin{abstract}
According to various analyses, Badan Penyelenggara Jaminan Sosial Kesehatan (BPJS) is experiencing a significant deficit. Inefficiency in the use of drugs in health services, including prescribing and using antibiotics, creates a bigger burden for BPJS. In the term of these conditions, quality and cost control is necessary to be done. RASPRO is an antibiotic stewardship program that can be used as an alternative to increase the effectiveness of antibiotic quality and cost control as listed in PERMENKES 8/2015 concerning antibiotic resistance control as an effort to reduce BPJS costs.
\end{abstract}

Keywords: RASPRO, Antibiotic, Quality, Cost, BPJS

Abstrak: Badan Penyelenggara Jaminan Sosial (BPJS) Kesehatan pada berbagai analisis dikatakan mengalami defisit yang cukup signifikan. Ketidakefisienan penggunaan obat-obatan dalam pelayanan kesehatan, termasuk peresepan dan penggunaan antibiotik menjadi salah satu beban yang harus ditagihkan oleh rumah sakit kepada kepada BPJS. Kendali mutu dan kendali biaya sangatlah diperlukan. RASPRO merupakan sistem tata guna antibiotik yang dapat digunakan sebagai alternatif untuk dapat meningkatkan efektifitas kendali mutu dan kendali biaya sesuai dengan indikator-indikator yang tercantum dalam PERMENKES 8 / 2015 tentang pengendalian resistensi antibiotik sebagai upaya untuk menurunkan beban biaya BPJS.

Kata Kunci: RASPRO, Antibiotik, Mutu, Biaya, BPJS

\section{PENDAHULUAN}

Dadgostar (2019) menyampaikan proyeksi angka kematian akibat resistensi antibiotik di seluruh dunia mencapai 10.000 jiwa, dengan penyumbang terbesar dari kawasan Asia yang mencapai 4.730 .000 jiwa. Sementara itu, Center of Disease Control (CDC) menyatakan estimasi kerugian akibat timbulnya resistensi antibiotik di Amerika Serikat mencapai 55.000 .000 dollar / tahun. Inan et al. (2005) menyampaikan bahwa belanja antibiotik harian akibat infeksi nosokomial di rumah sakit mencapai 89,64 dollar. Rerata penggunaan antibiotik harian untuk pneumonia mencapai 99,02 dollar, 94,32 dollar untuk infeksi aliran darah primer, 94,31 dollar untuk infeksi daerah operasi 52,37 dollar untuk infeksi saluran kemih 
dan 162,35 dollar untuk infeksi lainnya per pasien.

Di Indonesia saat ini beban biaya masalah kesehatan sangatlah besar. Badan Penyelenggara Jaminan Sosial (BPJS) Kesehatan pada sebuah analisis dikatakan mengalami defisit yang cukup signifikan. Firdaus dan Wondabio (2019) menyebutkan beberapa hal yang menyebabkannya, antara lain adalah mismatch antara pendapatan iuran dan beban manfaat, premi kepesertaan berada dalam posisi underpriced, besarnya tunggakan iuran pembayaran iuran kepesertaan, besarnya biaya pelayanan kesehatan yang disebabkan oleh banyaknya penduduk yang menderita penyakit kronis. Mismatch antara pendapatan iuran dan beban manfaat bisa menjadi lebih berat bila terdapat ketidakefisienan penggunaan obatobatan dalam pelayanan kesehatan, termasuk peresepan dan penggunaan antibiotik yang menjadi salah satu beban yang harus ditagihkan oleh rumah sakit kepada kepada BPJS. Oleh karena itu dalam hal ini kiranya sangatlah penting untuk rumah sakit agar dapat meningkatkan efisiensi peresepan antibiotiknya.

Sementara itu, data hasil survei tahun 2012 menunjukkan penurunan penggunaan dari penggunaan antibiotik yang tidak tepat, tetapi prevalensi (kejadian infeksi) dari kuman-kuman resisten antibiotik (Hadi et al. 2013). Oleh karenanya, semua rumah sakit di Indonesia wajib melakukan pengendalian resistensi antibiotik dengan mengontrol peresepan antibiotik, sehingga menjadi lebih bijak demi terkendalinya resistensi antibiotik di rumah sakit (Peraturan Menteri Kesehatan Republik Indonesia Nomor 8 Tahun 2015). Pengendalian resistensi antibiotik di setiap rumah sakit di seluruh Indonesia telah menjadi salah satu syarat yang dikaji dalam proses akreditasi rumah sakit berdasarkan Standar Nasional Akreditasi Rumah Sakit (SNARS) edisi 1 tahun 2018 (Natadidjaja, Widodo, et al. 2019). Untuk melaksanakan program pengendalian resistensi antibiotik di rumah sakit memerlukan komitmen pihak manajemen rumah sakit dalam penerapan pedoman pencegahan dan pengendalian infeksi yang telah dibuat. Hal ini harus didukung oleh pemenuhan sarana dan prasarana, kepatuhan praktisi rumah sakit pada pedoman program pengendalian antibiotik, serta pembentukan survei penggunaan antibiotik ((Rukmini, Siahaan, and Sari 2019) dan (Handayani, Siahaan, and Herman 2017)).

Natadidjaja et al. (2019) melalui survei yang dilakukan pada 156 rumah sakit di Indonesia mendapatkan sebanyak 114 rumah sakit belum melaksanakan program pengendalian resistensi antibiotik. Sementara itu, 107 dari 114 rumah sakit yang belum melaksanakan program pengendalian resistensi antibiotik menyatakan membutuhkan konsep program yang jelas dalam pelaksanaan program pengendalian resistensi antibiotik. Untuk dapat menjalankan program pengendalian resistensi antibiotik dibutuhkan buku Panduan Penggunaan Antibiotik (PPAB) yang harus didukung dengan sistem yang disepakati bersama dalam peresepan antibiotik intra rumah sakit. PPAB dengan sistem peresepan antibiotik di rumah sakit disebut sebagai sistem tataguna antibiotik. Permasalahan utama saat ini, di seluruh dunia masih belum ada model sistem tata guna antibiotik yang baku. Sistem tata guna antibiotik dilaksanakan berdasarkan kesepakatan masing-masing rumah sakit sesuai dengan manajerial, fasilitas, sosiodemografi, pola kuman dan sebagainya, yang berbedabeda satu dengan yang lainnya.

\section{Pelaksanaan Program Pengendalian Resistensi Antibiotik dengan Sistem Tata Guna Antibiotik}

Program pengendalian resistensi antibiotik adalah sebuah program yang harus dicanangkan oleh setiap rumah sakit berdasarkan kesepakatan bersama intra rumah sakit dalam persepan antibiotik oleh para dokter yang bekerja di rumah sakit tersebut. Dalam hal ini, rumah sakit harus memiliki Komite 
Pengendalian Resistensi Antimikroba (KPRA) intra rumah sakit yang dapat mengatur para dokter dalam meresepkan antibiotik secara bijak. Rumah sakit melalui KPRA-nya diharuskan membuat Panduan Penggunaan Antibiotik (PPAB) yang disepakati bersama yang harus menjadi acuan bagi para dokter dalam peresepan antibiotik dalam praktek sehari-hari. Penggunaan PPAB harus didukung dengan sistem peresepan antibiotik yang disebut sebagai sistem tata guna antibiotik.

LaRocco (2003) dalam Stevenson et al.

(2012) menjelaskan adanya review catatan medis dengan pemberian feedback peresepan antibiotik pada para dokter pada sistem tata guna antibiotiknya terbukti menurunkan rerata biaya penggunaan antibiotik sebesar 18,21 dollar menjadi 14,77 dollar per pasien. Penelitian Ansari et al (2003) dalam Stevenson et al. (2012), dengan mengambil data selama 2 tahun di Skotlandia, menyatakan bahwa adanya audit penggunaan antibiotik oleh farmasis disertai dengan monitoring dan pengawasan waktu penggunaan antibiotik untuk pasienpasien di rumah sakit telah menghemat biaya sebesar 577.488 poundsterling. Length of Stay (LOS) atau lama tinggal pasien di rumah sakit juga menjadi indikator kendali mutu dan kendali biaya dalam penggunaan antibiotik di rumah sakit ((Stevenson et al. 2012) dan (Munarsih, Natadidjaja, and Syamsudin 2018)).

Munarsih et al. (2018) melalui sebuah kajian retrospektif menyatakan kelompok dengan infeksi paru komunitas yang diresepkan antibiotik tidak sesuai dengan PPAB memiliki LOS di rumah sakit lebih lama dibandingkan kelompok dengan infeksi paru komunitas yang diresepkan antibiotik sesuai dengan PPAB (OR $=10.25 ; 95 \% \mathrm{Cl}: 3.93-26.71 ; p<0.001)$. Melalui studi terdahulu yang menempatkan LOS sebagai salah satu indikator kendali mutu dan biaya antibiotik, maka kajian ini dapat menjadi sebuah preliminary study untuk dilanjutkan dalam penilaian Cost Benefit Analysis (CBA). Penilaian CBA dapat dilakukan dengan membandingkan jumlah episode pemanjangan
LOS yang dapat dicegah dengan total biaya pelaksanaan sistem tataguna antibiotik. Penilaian CBA dapat dilakukan sebagai salah satu bentuk parameter farmakoekonomi (Trisna 2016).

Guerri-Fernandez et al. (2016) melalui studi kuasi-eksperimental membandingkan 2 model sistem tata guna antibiotik terhadap parameter LOS pada 2 bangsal bedah di rumah sakit. Model A adalah model pre intervensi, tanpa sistem panduan dengan melakukan kajian peresepan antibiotik paska peresepan, dibandingkan dengan Model $\mathrm{B}$ adalah model intervensi dengan sistem panduan bagi para dokter dengan audit prospektif sejak awal antibiotik diberikan. Rerata LOS Model A adalah 14,7 hari $(95 \% \mathrm{Cl}: 7-16.5 ; \mathrm{p}<0.05)$ sementara rerata LOS Model B adalah 10,7 hari $(95 \%$ Cl: 613; $p<0.05)$. Tidak ada perbedaan signifikan dalam angka kematian antara kedua model.

Di Indonesia, Peraturan Menteri Kesehatan Republik Indonesia Nomor 82015 menjelaskan bahwa indikator mutu pelaksanaan program pengendalian antibiotik di rumah sakit adalah adanya perbaikan kualitas penggunaan antibiotik (kendali mutu) dan perbaikan kuantitas penggunaan antibiotik (kendali biaya). Parameter kendali mutu penggunaan antibiotik diukur dengan menggunakan alur Gyssens, sementara kuantitas penggunaan antibiotik di rumah sakit dinilai dengan menghitung total jumlah peresepan antibiotik dan penghitungan World Health Organization (WHO) Defined Daily Dose (DDD) / 100 patient days yang menjadi sebuah standar baku untuk penilaian kuantitas penggunaan antibiotik.

\section{METODA}

Studi ini merupakan sebuah tinjauan literatur yang membahas penelitian-penelitian terdahulu terkait intervensi sistem tata guna antibiotik RASPRO di rumah sakit. Regulasi Antimikroba Sistem Prospektif (RASPRO) merupakan sebuah konsep tools berupa tabel untuk pengaturan penggunaan antibiotik empirik dan definitif prospektif di rumah sakit yang bertujuan 
untuk mengoperasionalkan peraturan di atas. Indikator perbaikan penggunaan antibiotik yang digunakan adalah penurunan DDD dan unit penjualan antibiotik sesuai SNARS (Natadidjaja, Fitra, et al. 2020). RASPRO adalah sebuah sistem tata guna antibiotik dengan intervensi pemberian panduan bagi para dokter dalam peresepan antibiotik. Antibiotik akan direstriksi (tidak dikeluarkan) bila peresepan antibiotik tidak sesuai dengan sistem. Demikian pula bila ada penggunaan antibiotik berkepanjangan, maka secara otomatis farmasi akan menghentikan pengeluaran antibiotiknya, kecuali dokter bisa menjelaskan alasannya dengan mengisi formulir pada sistem tersebut.

Secara garis besar RASPRO memiliki 4 formulir. Formulir yang pertama disebut sebagai formulir RASPRO Alur Antibiotik Awal (RASAL), formulir yang harus diisi oleh semua dokter yang meresepkan antibiotik pertama pada seorang pasien di ruang rawat inap. Formulir ini akan mengarahkan dokter pada jenis antibiotik apa yang harus diresepkan berdasarkan PPAB yang berlaku di rumah sakit tersebut. Formulir kedua disebut formulir RASPRO Alur Antibiotik Lanjutan (RASLAN). Formulir RASLAN wajib diisi oleh dokter apabila hendak mengganti antibiotik untuk pasien yang dirawat di ruang rawat inap. Maksimal formulir RASLAN hanya boleh digunakan sebanyak 2 kali. Formulir ketiga adalah formulir RASPRO Antibiotik Berkepanjangan (RASPRAJA) yang harus diisi oleh dokter apabila peresepan antibiotik di rawat inap terhadap seorang pasien lebih dari 7 hari. Formulir RASPRAJA maksimal hanya digunakan 2 kali. Formulir keempat adalah formulir RASPRO Antibiotik sesuai Kultur (RASPATUR). Formulir RASPATUR wajib diisi dokter apabila antibiotik akan diresepkan berdasarkan temuan kuman yang diambil dari spesimen pasien yang dirawatnya di ruang rawat inap. Formulir RASPATUR juga digunakan maksimal sebanyak 2 kali. Apabila formulir RASLAN, RASPRAJA, dan RASPATUR digunakan sebanyak > 2 kali, maka akan dilakukan pertemuan khusus untuk melakukan kajian kasus penggunaan antibiotik oleh KPRA kepada dokter yang bersangkutan. RASPRO yang dilengkapi dengan 4 jenis formulir ini diharapkan menjadi sebuah tata guna antibiotik di rumah sakit yang dapat memandu para dokter agar dapat menggunakan antibiotik sesuai PPAB, sehingga penggunaan antibiotik menjadi lebih bijak, demi tercapainya kendali mutu dan kendali biaya antibiotik di rumah sakit (Natadidjaja 2019, 2020).

\section{HASIL}

\section{Dampak Terapan Sistem Tataguna Antibiotik RASPRO dalam Kendali Mutu dan Kendali Biaya}

Beberapa studi dari RASPRO Indonesia Study Group mengenai kualitas penggunaan antibiotik di rumah sakit terhitung cukup baik. Studi antara lain dilakukan oleh Sundariningrum et al. (2020) di sebuah rumah sakit swasta menunjukan kualitas penggunaan antibiotik bijak di unit intensif anak (perinatologi) mencapai $63.03 \%$ dengan metode RASPRO yang diukur pada alur Gyssens. Natadidjaja et al. (2020) melalui presentasi abstrak penelitian kuasi eksperimental 3 bulan pre-post terapan RASPRO, yang disampaikan pada International Federation of Infection Control (IFIC) Congress menyatakan adanya penurunan peresepan antibiotik yang tidak bijak dari $65,45 \%$ menjadi $27,37 \%$ dari semua total antibiotik yang digunakan di rawat inap sebuah rumah sakit di Jawa Tengah. Penggunaan formulir-formulir RASPRO sebagai sistem tata guna antibiotik mungkin dapat pula dijadikan sebuah pedoman untuk pelaporan kepada BPJS bahwa antibiotik yang digunakan dan yang di-reimburse memang sudah sesuai indikasi. Melalui studi ini, Natadidjaja et al. (2020) juga menyampaikan penurunan rerata penggunaan antibiotik per pasien rawat inap sebanyak $15,44 \%$ pada 3 bulan sebelum dan sesudah konsep RASPRO diterapkan. Walaupun demikian, DDD/100 
patient days antibiotik golongan Quinolon (Levofloxacin) meningkat dari 2,38 menjadi 15,26, sementara DDD / 100 patient days antibiotik golongan Cephalosporin turun dari 19,88 menjadi 15,41.

Pada studi terdahulu, Natadidjaja et al. (2019), melalui abstrak pada International Congress of Prevention \& Infection Control (ICPIC), sebuah studi kuasi eksperimental 3 bulan pre-post terapan RASPRO di sebuah rumah sakit mendapatkan adanya penurunan signifikan penggunaan antibiotik spektrum luas dari 1.339 ampul menjadi 326 ampul atau sebesar $75,65 \%$ di rawat inap. Analisis farmakoekonomi melalui Cost Effectiveness Analysis (CEA): Average Cost Effectiveness Ratio (ACER) dan Incremental Cost Effectiveness Ratio (ICER) belum dapat disimpulkan pada studi tersebut, karena memang belum terdapat kajian efektifitas per cure dari setiap antibiotik yang diberikan. Namun diharapkan melalui penurunan jumlah peresepan antibiotik tersebut, terjadi penurunan beban biaya yang harus ditanggung oleh BPJS.

Pada penelitian lain, Natadidjaja et al. (2020) memperlihatkan penurunan signifikan DDD / 100 patient days antibiotik spektrum luas Meropenem dari 16,93 menjadi 7,39, penurunan DDD/100 patient days antibiotik Ceftriaxone dari 37,85 menjadi 14,41 dan penurunan total $D D D / 100$ patient days antibiotik dengan peningkatan $D D D / 100$ patient days Levofloxacin 12,93 menjadi 24,26 paska sosialisasi PPAB tanpa sistem tataguna antibiotik. Sementara itu, 3 bulan paska sosialisasi PPAB dengan sistem tata guna antibiotik konsep RASPRO, penurunan peresepan antibiotik golongan Cephalosporin dan Meropenem mencapai $28,90 \%$ pada proyek uji coba di sebuah rumah sakit.

\section{PENUTUP}

Ketidakefisienan penggunaan obatobatan dalam pelayanan kesehatan, termasuk peresepan dan penggunaan antibiotik yang overuse dapat menjadi salah satu beban tersendiri bagi BPJS. Saat ini dibutuhkan suatu sistem tata guna antibiotik untuk dapat melaksanakan program pengendalian resistensi antibiotik. Namun, di seluruh dunia masih belum ada model sistem tata guna antibiotik yang baku. RASPRO merupakan sistem tata guna antibiotik yang dapat digunakan sebagai alternatif untuk dapat meningkatkankan efektifitas kendali mutu dan kendali biaya sesuai dengan indikatorindikator yang tercantum dalam Peraturan Menteri Kesehatan Republik Indonesia Nomor 8 2015 tentang pengendalian resistensi antibiotik. Hal ini juga dalam rangka menurunkan beban biaya antibiotik yang harus ditagihkan rumah sakit kepada BPJS.

\section{REFERENCES:}

Dadgostar, Porooshat. 2019. "Antimicrobial Resistance: Implications and Costs." Infection and Drug Resistance 12: 3903-10. https://doi.org/10.2147/IDR.S234610.

Firdaus, Kekeu Kirani, and Ludovicus Sensi Wondabio. 2019. "Analisis luran Dan Beban Kesehatan Dalam Rangka Evaluasi Program Jaminan Kesehatan." Jurnal Aset (Akuntansi Riset) 11 (1): 147-58. https://doi.org/https://doi.org/10.17509/jaset.v11i1.

Güerri-Fernández, R., J. Villar-García, S. Herrera-Fernández, M. Trenchs-Rodríguez, J. Fernández-Morato, L. Moro, J. Sancho, et al. 2016. "An Antimicrobial Stewardship Program Reduces Antimicrobial Therapy Duration and Hospital Stay in Surgical Wards." Revista Espanola de Quimioterapia : Publicacion Oficial de La Sociedad Espanola de Quimioterapia 29 (3): 119-22.

Hadi, Usman, Kuntaman Kuntaman, Mariyatul Qiptiyah, and Hari Paraton. 2013. "Problem of Antibiotic Use and Antimicrobial Resistance in Indonesia: Are We Really Making Progress?" Indonesian Journal of Tropical and Infectious Disease 4 (4): 5-8. https://doi.org/10.20473/ijtid.v4i4.222. 
Handayani, Rini Sasanti, Selma Siahaan, and Max Joseph Herman. 2017. "Resistensi Antimikroba Dan Penerapan Kebijakan Pengendalian Di Rumah Sakit Di Indonesia." Jurnal Penelitian Dan Pengembangan Pelayanan Kesehatan 1 (2): 131-40. https://doi.org/10.22435/jpppk.v1i2.8101.131-140.

Inan, Dilara, Rabin Saba, Filiz Gunseren, Gozde Ongut, Ozge Turhan, Ata Nevzat Yalcin, and Latife Mamikoglu. 2005. "Daily Antibiotic Cost of Nosocomial Infections in a Turkish University Hospital." BMC Infectious Diseases 5: 1-6. https://doi.org/10.1186/1471-2334-5-5.

Munarsih, Fetri Charya, Ronald Irwanto Natadidjaja, and Syamsudin Syamsudin. 2018. "Pengaruh Pemberian Antibiotik Berdasar Panduan Terhadap Lama Tinggal Pada Pasien Pneumonia Komunitas Di Rumah Sakit." Jurnal Penyakit Dalam Indonesia 5 (3): 141. https://doi.org/10.7454/jpdi.v5i3.195.

Natadidjaja, Ronald Irwanto. 2019. "Translasi Antibiogram Kumulatif Ke Dalam Bentuk Panduan Penggunaan Antibiotik ( PPAB ) Dan Implementasi Konsep RASPRO Dalam Tataguna Antibiotik Di Rumah Sakit." In The 11th Continuing Professional Development on Clinical Pathology and Laboratory Medicine and Medical Equipment EXPO 2019: "Universal Health Coverage 2019," edited by Yuwono Hadisuparto, Tonang Dwi Ardyanto, Dian Ariningrum, Amiroh Kurniati, Sienny Linawati, and Pik Siong, 150-56. Surakarta: Penerbitan dan Pencetakan UNS (UNS Press). www.unspress.uns.ac.id.

- 2020. Konsep RASPRO: Metode Tata Guna Antibiotik Bijak Dalam Rangka Menjalankan Fungsi PPRA Di Rumah Sakit. Jakarta: PT Penerbit Erlangga.

Natadidjaja, Ronald Irwanto, Yuhana Fitra, Aziza Ariyani, Rika Bur, and Nugroho Budi Santoso. 2020. "Konsep RASPRO : Upaya Melaksanakan Amanah Permenkes 8 / 2015 Untuk Menurunkan Kuantitas Penggunaan Antibiotik." Journal of Hospital Accreditation 02 (4): 57-62. https://doi.org/https://doi.org/10.35727/jha.v0ixx.24.

Natadidjaja, Ronald Irwanto, Yuhana Fitra, Yudianto Budi Saroyo, and Augustine Matatula. 2019. "DECREASING THE BROAD SPECTRUM ANTIBIOTICS UNIT SOLD: THE PROSPECTIVE ANTIMICROBIAL STEWARDSHIP OF RASPRO INDONESIA MODEL." Antimicrobial Resistance \& Infection Control 8 (S1): 147-48. https://doi.org/10.1186/s13756-019-0567-6.

Natadidjaja, Ronald Irwanto, Tarcisius Henry, Hadianti Adlani, Aziza Ariyani, and Rika Bur. 2020. "Increasing the Antibiotic Prudent Use in a Private Hospital in Central Java: RASPRO Best Practice Implementation." International Journal of Infection Control 16: 26. https://www.ijic.info/article/view/20165/13507.

Natadidjaja, Ronald Irwanto, Djoko Widodo, Aziza Ariyani, and Hadianti Adlani. 2019. "Survei Persepsi Kebutuhan Dan Hambatan Rumah Sakit Dalam Menjalankan Fungsi Panitia Pengendalian Resistensi Antibiotik." Journal of Hospital Accreditation 1 (2): 36-40. https://doi.org/10.35727/jha.v1i2.40.

Peraturan Menteri Kesehatan Republik Indonesia Nomor 8. 2015. Peraturan Menteri Kesehatan Republik Indonesia Nomor 8 Tahun 2015 Tentang Program Pengendalian Resistensi Antimikroba Di Rumah Sakit.

Rukmini, Selma Siahaan, and Ida Diana Sari. 2019. "Analisis Implementasi Kebijakan Program Pengendalian (Studi Kasus Di RSUP Dr. Wahidin Sudirohisudo , Makassar)." Puslitbang Humaniora Dan Manajemen Kesehatan, 106-16. https://doi.org/http://dx.doi.org/10.22435/hsr.v22i2.1038.

Stevenson, Kurt B., Joan-Miquel Balada-Llasat, Karri Bauer, Meredith Deutscher, Debra Goff, Mark Lustberg, Preeti Pancholi, et al. 2012. "The Economics of Antimicrobial Stewardship: The Current State of the Art and Applying the Business Case Model." Infection Control \& Hospital Epidemiology 33 (4): 389-97. https://doi.org/10.1086/664910.

Sundariningrum, Rinna Wamilakusumayanti, Darmawan Budi Setyanto, and Ronald Irwanto Natadidjaja. 2020. "Evaluasi Kualitatif Antibiotik Metode Gyssens Dengan Konsep Regulasi Antimikroba Sistem Prospektif RASPRO Pada Pneumonia Di Ruang Rawat Intensif Anak." Sari Pediatri 22 (2): 109. https://doi.org/10.14238/sp22.2.2020.109-14.

Trisna, Yulia. 2016. "Aplikasi Farmakoekonomi." Ikatan Apoteker Indonesia. http://iai.id/news/artikel/aplikasifarmakoekonomi. 